\title{
ARDUINO BASED WIRELESS SENSOR NETWORK SYSTEMS FOR AGRICULTURE
}

Kalpana Murugan

Department of Electronics and Communication Engineering, School of Electronics and Electrical

Technology, Kalasalingam Academy of Research and Education, Krishnankoil, Virudhunagar (Dt), (India).

E-mail:drmkalpanaece@gmail.com

ORCID: https://orcid.org/0000-0002-5121-0468

R. Alaguselvi

Department of Electronics and Communication Engineering, School of Electronics and Electrical

Technology, Kalasalingam Academy of Research and Education,

Krishnankoil, Virudhunagar (Dt), (India).

E-mail: alaguselvir3@gmail.com

ORCID: https://orcid.org/0000-0002-7909-549X

Recepción: 16/10/2019 Aceptación: 11/09/2020 Publicación: 30/11/2021

\section{Gitación sugerida:}

Murugan, K., y Alaguselvi, R. (2021). Arduino based wireless sensor network systems for agriculture. 3C Tecnología. Glosas de innovación aplicadas a la pyme, Edición Especial, (noviembre, 2021), 87-97. https:/ / doi.org/10.17993/3ctecno.2021.specialissue8.87-97 


\section{ABSTRACT}

Now a day's agriculture is the most important significant role in the society for the last few decades. Farmers mainly depend upon the agriculture for their daily lively hood. Main aim of this work is to measure the various parameters of agriculture are soil moisture, temperature, humidity and gas. This work proposes a Smart TMHG Measurement System, to measure the values of Temperature, Moisture, Humidity and Gas. Initially soil moisture sensor, humidity sensors, gas sensor and water pump which is connected to arduino. These measured values are displayed in Liquid Grystal Display (LCD). After detecting soil moisture and Humidity level, dc pump will be on or off based on the measured value. Arduino module control the ON or OFF the motor pump using an embedded c program. This information will be send to the user with the help of Wireless Sensor Network (WSN) for taking remedial action. Smart TMHG Measurement System will make farmers to increase the crop for better yield and make them economically benefit. Smart TMHG Measurement System used to measure the parameters of soil moisture, temperature, humidity and gas in remote location by using wireless sensor network which will help the community of farmer on service based, to reduce the cost, rather than the other sources.

\section{KEYWORDS}

Wireless Sensor Network, Soil moisture, Humidity, Temperature, Gas, Arduino Board, LCD display. 


\section{INTRODUCTION}

Water shortage is one of the major problems in world. Many different methods are incorporated for conservation of water. Water is essential for each and every field of crop, every human being, plants, animals etc., in an agriculture water place a vital role for yield crops. For cropping yield excess of water is given to the field, Wastage of water is a major problem in agriculture. So, a number of techniques are available to save or to control the wastage of water. Wireless sensor network (WSN) is a small, inexpensive, low power and distributed devices which are capable of local processing and wireless communications are used for various applications like environmental monitoring, habitat monitoring, seismic detection, health care, Industrial monitoring, home automation etc.

Ditch Irrigation is the old methodology, where ditches are dug out by us and seedlings are planted in horizontal manner aligned pattern. Water is made to move to different canals via siphon tubes. These are mainly used in olden days. The water can be saved by using this method. Water is given near the roots itself then the roots can observe the water how much it needed. Instead of allowing water around the tree or crops up to certain distance. Through this methodology water can be saved effectively.

It is a very tough process and also labor is more involved and investment will be high for laboring purpose. In this process the field is cut into the multiple steps and supported by keeping of walls while the plain areas are used for plantation and the idea is that the water runs down each step watering each column. If the user is in travelling, then this type of automatic irrigation method is helpful for sending water to the land automatically and stops sending water when the crop is not needed.

The work of Kim, Evans and Iversen (2008) represents real time monitoring and control of variable rate irrigation controller. The sensor nodes measure environmental parameter and transmit data to base station where base station process data through a user-friendly decision making program and all data commands send to irrigation control station.

Nandurkar, Thool and Thool (2014) represents the design of smart sprinkler system using mesh capable WSN for monitoring and control of field irrigation system. This system provides accuracy by controlling the soil moisture level between the thresholds. Sensor 
nodes send data to base station every time the timer variable overflows. Base station has an actuator interface to control solenoid valve using Graphical User Interface (GUI). Rinnovando group (Rgroup) is working with agriculture experts that concentrate on monitoring microclimate in tomato greenhouse proposed in Mancuso and Bustaffa (2006). The main goal of monitoring is to measure when the crop is on risk of developing and the farmer treat the field with fertilizer only when needed.

Thilagavathi (2013) proposed a WSN based system that provides online system to control and maintain the farm remotely by logging into a farming website. Cameras used to capture live videos of the farm. By using these videos, the user able to see the real condition of the farm and control the farm remotely from any part of the world.

Kodali and Muraleedhar (2015) represents the overall history of spices as black pepper, cardamom and clove in different states where these spices are cultivated and exporters of spices and the problem faced by farming community related to pest and irrigation. Indigenous design and development of Wireless Sensor and Actuator Network (WSAN) is proposed in Shaikh et al. (2010).

For better control of irrigation process in third world countries like Pakistan, it is necessary to develop cost effective hardware system. They design system using three components as sensor node to sense data, Actuator node for switching on/off of the connected actuator devices and sink nod for gathering data for decision- making.

Singh, Chyan and Sebastian (2010) represents the design of a system which takes soil samples when an event triggered with an outside event such as rain event. The system has variable sampling rates with interface to soil sensors and rain gauge. Wireless soil sensor network monitor an event of rain and soil moisture content. Such system consists of rain detection module and sensory module.

Martinelli et al. (2009) represents the use of WSN that provide real time data collected by sensor node. Each node collect data concerned with the voltage of the battery, internal voltage and current provided by solar panel and the temperature of the microcontroller to perform real time monitoring of the network stated. After measured data, the sensor board is switches off and RF sends the collected data over radio channel to sink node. Design of 
water saving irrigation control system based on WSN which is the combination of fuzzy logic and neural network. Fuzzy logic is a mathematic model and neural network that has self-learning ability to adapt changing environment. Fuzzy neural network is an integrated set of fuzzy logic reasoning ability and powerful self-learning ability of neural network. Sensor nodes measure soil moisture, temperature, humidity, light intensity and through LAN or WAN data transmitted to gateway node to upper machine and irrigation control system control electromagnetic valve to precision irrigation according to real time feedback information collected by measuring data.

\section{RELATED WORK}

Rani and Kamalesh (2014) represents the design of distributed control system of indoor wireless temperature and humidity to improve the overall performance of the system to detect change in the temperature and humidity. Design of an adaptive irrigation controller using WSN for monitoring the soil moisture status and controlling the irrigation program schedule is proposed in Shaikh et al. (2010).

Singh et al. (2010) proposes tree topology and cluster based multi-hop routing algorithm to reduce energy consumption while data transmission of nodes uses WSN for monitor and collect crop water requirements such as temperature, humidity, soil moisture and irrigation volume to build the machine learning model and data aggregation.

Design of an automated irrigation system using WSN including soil moisture sensor, air temperature sensor and air humidity sensor in order to collect environmental data and controlling the irrigation system is proposed in Ameer et al. (2015). By using smart phone, the irrigation system uses values to turn on/off the solenoid valve.

Wan (2012) analyses the use of Programmable System-On-Chip (PSoG) technology as a part of WSN to monitor and control various greenhouse parameter. The author discuss the problem faced by management server as like data, congestion and intercommunication between nodes. WSN based applications used with a specific protocol and system on chip-based hardware with programmable radio (Yao et al., 2010). It combines sensors and actuators in a WSN for successful deployment of WSN for Precision Agriculture. To charge electrical devices, it used solar photovoltaic and rechargeable batteries. 
Zhang and Chang (2011) present the implementation of GPRS communication as a gateway between WSN and internet. Artificial immune systems connected to the internet by using GPRS. Various data transmission approaches are used to implement closed loop Irrigation system within Precision Agriculture. Closed loop irrigation system is used to apply correct amount of water in correct place at right time and save the natural resources.

In the work of Zhang and Chang (2011) the system is modeled in outdoor environment using Tiny OS based IRIS motes to measure the moisture level of the paddy field. Moisture sensors measure the soil moisture level. The system sets a threshold value; if the voltage exceeds that threshold then it represents the driest soil. This system has better visualization and monitoring GUI. In order to overcome all the above drawbacks, Smart TMHG measurement system is proposed.

\section{MATERIALS AND METHODS}

\subsection{SMART TMHG MEASUREMENT SYSTEM}

Smart TMHG Measurement System is mainly used to measures the values of Temperature, Moisture, Humidity and Gas. These measured values are displayed in LCD display. Initially soil moisture and Humidity sensors are dip in to the soil, which is connected to arduino. Measuring all the values, it will be displayed in the LCD. After detecting soil moisture and Humidity level condition, dc pump will be on or off. This information will be send to the user with the help of WSN for taking remedial action. To switch ON or OFF the motor pump an embedded c program in the arduino module is used. Main objective of this proposed method is that to help the community of people on service based to reduce the cost rather than the other sources. 


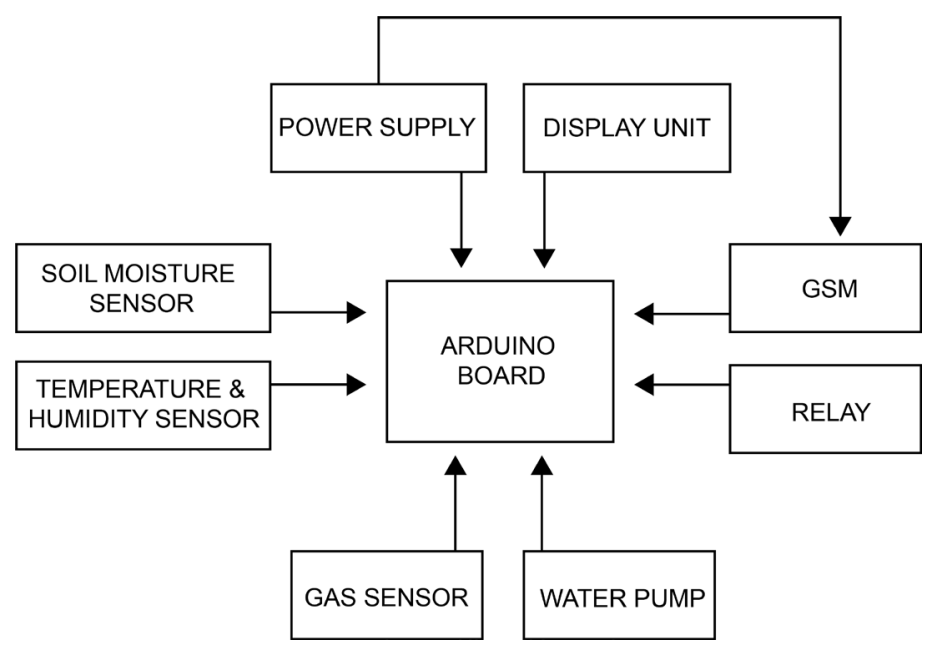

Figure 1. Block Diagram.

Source: own elaboration.

Plant sample is fixed with an individual soil moisture sensor. Each plant sample demands different moisture conditions. The Arduino module is used to read the analog input values from the four sensors placed in the samples. The pumps are switched off under normal conditions and are programmed to operate only when the soil moisture goes below certain threshold levels which are specific to the plant. The Arduino interface controls the working of the pumps which continue to irrigate the fields till the moisture levels exceed the upper threshold value. Simultaneously, the status of the active pump is indicated in the mobile phone of the user. This is entirely controlled by the Node MCU module. The automatic refresh feature of this module helps in continuous updating of all the three pumps on the mobile phone screen.

\section{RESULTS}

SMART TMHG MEASUREMENT SYSTEM is implemented in real time. Soil Moisture, Humidity, Temperature and gas measured by using an aurdino board. The main aim of the project is that measuring the parameters and knowing the farmer that how much amount should be present in the atmosphere. Wireless Sensor network is used to implement this work. The measured values are displayed in the LCD display. Output of Real Time Implementation as shown in Figure 2. 


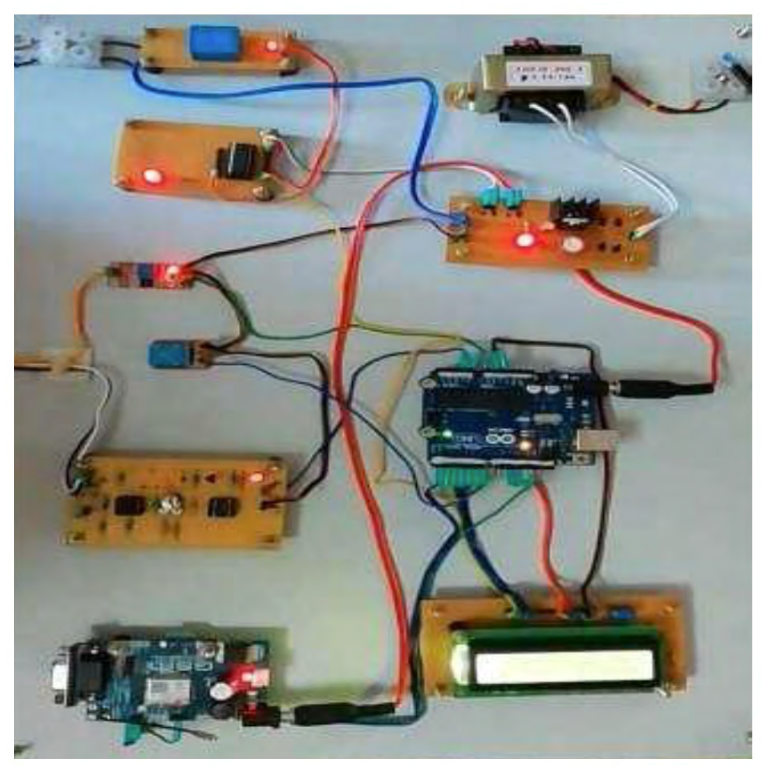

Figure 2. Output for Arduino Based Agriculture.

Source: own elaboration.

\section{CONCLUSIONS}

This work proposes a Smart TMHG Measurement System to measure the various parameters of agriculture field like soil moisture, temperature, humidity and gas. These measured values are displayed in LCD. After detecting the soil moisture and Humidity level, dc pump will be on or off based on the measured value. Arduino module control the ON or OFF the motor pump using an embedded c program. The pumps are switched off under normal conditions, when the soil moisture goes below certain threshold levels the pump goes $\mathrm{ON}$, it was programmed in arduino module. The Arduino interface controls the working of the pumps which continue to irrigate the fields till the moisture levels exceed the upper threshold value. This information sent to the user with the help of WSN for taking remedial action. The Smart TMHG Measurement System will make farmers to increase the crop for better yield and make them economically $(90 \%)$ benefit in remote location by using WSN. 


\section{ACKNOWLEDGEMENT}

We would like to thank International Research Center of Kalasalingam Academy of Research and Education for providing financial assistance under the scheme of University Research Fellowship(URF) and we also thank the Department of Electronics and Communication Engineering of Kalasalingam Academy of Research and Education, India for permitting to use the computational facilities available in Signal Processing and VLSI Design which was setup with the support of the Department of Science and Technology (DST).

\section{REFERENCES}

Ameer, S., Chaubey, S. S., Joseph, M., Rajasekhar, P., Abhinav, S., \& Ravikiran, R. (2015). Notice of Retraction Automatic irrigation system through a solar power. In International Conference on Electrical, Electronics, Signals, Communication and Optimization, pp. 1-5, IEEE. https://doi.org/10.1109/EESCO.2015.7254015

Fazackerley, S., \& Lawrence, R. (2010). Reducing turfgrass water consumption using sensor nodes and an adaptive irrigation controller. In IEEE Sensors Applications Symposium, pp. 90-94, IEEE. https://doi.org/10.1109/SAS.2010.5439386

Kaewmard, N., \& Saiyod, S. (2014). Sensor data collection and irrigation control on vegetable crop using smart phone and wireless sensor networks for smart farm. In IEEE Conference on Wireless Sensors, pp. 106-112, IEEE. https://doi.org/10.1109/ ICWISE.2014.7042670

Kim, Y., Evans, R. G., \& Iversen, W. M. (2008). Remote sensing and control of an irrigation system using a distributed wireless sensor network. IEEE transactions on instrumentation and measurement, 57(7), 1379-1387. https://doi.org/10.1109/ TIM.2008.917198

Kodali, R. K., \& Muraleedhar, A. (2015). WSN in spice cultivation. In International Conference on Green Computing and Internet of Things, pp. 1173-1177, IEEE. https:// doi. org/10.1109/ICGCIoT.2015.7380640 
Mancuso, M., \& Bustaffa, F. (2006). A wireless sensors network for monitoring environmental variables in a tomato greenhouse. In IEEE International Workshop on Factory Communication Systems, Vol. 10.

Martinelli, M., Ioriatti, L., Viani, F., Benedetti, M., \& Massa, A. (2009). A WSNbased solution for precision farm purposes. IEEE International Geoscience and Remote Sensing Symposium, 5, V-469. https://doi.org/10.1109/IGARSS.2009.5417630

Mat, I., Kassim, M. R. M., \& Harun, A. N. (2014). Precision irrigation performance measurement using wireless sensor network. In Sixth International Conference on Ubiquitous and Future Networks, pp. 154-157, IEEE. https://doi.org/10.1109/ ICUFN.2014.6876771

Nandurkar, S. R., Thool, V. R., \& Thool, R. G. (2014). Design and development of precision agriculture system using wireless sensor network. In First International Conference on Automation, Control, Energy and Systems, pp. 1-6, IEEE. https://doi. org/10.1109/TENCON.2015.7372834

Peng, X., \& Liu, G. (2012). Intelligent water-saving irrigation system based on fuzzy control and wireless sensor network. In Fourth International Conference on Digital Home, pp. 252-256, IEEE. https://doi.org/10.1109/ICDH.2012.13

Rani, M. U., \& Kamalesh, S. (2014). Web based service to monitor automatic irrigation system for the agriculture field using sensors. In International Conference on Advances in Electrical Engineering, pp. 1-5, IEEE. https://doi.org/10.1109/ICAEE.2014.6838569

Shaikh, Z. A., Yousuf, H., Nawaz, F., Kirmani, M., \& Kiran, S. (2010). Crop irrigation control using wireless sensor and actuator network (WSAN). In International Conference on Information and Emerging Technologies, pp. 1-5, IEEE. https://doi.org/10.1109/ ICIET.2010.5625669

Singh, A., Chyan, L. S., \& Sebastian, P. (2010). Sensor integration in a Wireless Sensor Network system for environmental monitoring system. In International Conference on Intelligent and Advanced Systems, pp. 1-5, IEEE. https://doi.org/10.1109/ ICIAS.2010.5716114 
Thilagavathi, G. (2013). Online farming based on embedded systems and wireless sensor networks. In International Conference on Computation of Power, Energy, Information and Communication, pp. 71-74, IEEE. https://doi.org/10.1109/ICGPEIC.2013.6778501

Wan, S. (2012). Research on the Model for Crop Water Requirements in Wireless Sensor Networks. In International Conference on Management of e-Commerce and e-Government, pp. 234-237. IEEE. https://doi.org/10.1109/ICMeCG.2012.77

Yao, Z., Lou, G., Zeng, X., \& Zhao, Q. (2010). Research and development precision irrigation control system in agricultural. International Conference on Computer and Communication Technologies in Agriculture Engineering, 3, 117-120. https://doi. org/10.1109/CGTAE.2010.5544390

Zhang, X., \& Chang, B. (2011). Research of temperature and humidity monitoring system based on WSN and fuzzy control. In International Conference on Electronics and Optoelectronics, 4, V4-300. https://doi.org/10.1109/ICEOE.2011.6013489 